\title{
Impact of promoting longer-lasting insecticide treatment of bed nets upon malaria transmission in a rural Tanzanian setting with pre-existing high coverage of untreated nets
}

\author{
Tanya L Russell*1,2,3, Dickson W Lwetoijera1,4, Deodatus Maliti1,3, Beatrice Chipwaza1, Japhet Kihonda1, J \\ Derek Charlwood ${ }^{5}$, Thomas A Smith 6 , Christian Lengeler6, Mathew A Mwanyangala', Rose Nathan', Bart GJ Knols ${ }^{7}$, \\ Willem Takken ${ }^{8}$ and Gerry F Killeen 1,2,3,6
}

\begin{abstract}
Background: The communities of Namawala and Idete villages in southern Tanzania experienced extremely high malaria transmission in the 1990s. By 2001-03, following high usage rates (75\% of all age groups) of untreated bed nets, a 4.2-fold reduction in malaria transmission intensity was achieved. Since 2006, a national-scale programme has promoted the use of longer-lasting insecticide treatment kits (consisting of an insecticide plus binder) co-packaged with all bed nets manufactured in the country.

Methods: The entomological inoculation rate (EIR) was estimated through monthly surveys in 72 houses randomly selected in each of the two villages. Mosquitoes were caught using CDC light traps placed beside occupied bed nets between January and December 2008 ( $n=1,648$ trap nights). Sub-samples of mosquitoes were taken from each trap to determine parity status, sporozoite infection and Anopheles gambiae complex sibling species identity.

Results: Compared with a historical mean EIR of 1400 infectious bites/person/year (ib/p/y) in 1990-94; the 2008 estimate of $81 \mathrm{ib} / \mathrm{p} / \mathrm{y}$ represents an 18-fold reduction for an unprotected person without a net. The combined impact of longer-lasting insecticide treatments as well as high bed net coverage was associated with a 4.6-fold reduction in EIR, on top of the impact from the use of untreated nets alone. The scale-up of bed nets and subsequent insecticidal treatment has reduced the density of the anthropophagic, endophagic primary vector species, Anopheles gambiae sensu stricto, by $79 \%$. In contrast, the reduction in density of the zoophagic, exophagic sibling species Anopheles arabiensis was only $38 \%$.
\end{abstract}

Conclusion: Insecticide treatment of nets reduced the intensity of malaria transmission in addition to that achieved by the untreated nets alone. Impacts were most pronounced against the highly anthropophagic, endophagic primary vector, leading to a shift in the sibling species composition of the A. gambiae complex.

\section{Background}

In much of Africa, where malaria transmission levels are extremely high, substantial reductions in the intensity of transmission are required for even a modest reduction in human parasitaemia [1,2]. Over the past decade, a major malaria control strategy has been the use of insecticide-

* Correspondence: t.russell2@uq.edu.au

1 Biomedical and Environmental Thematic Group, Ifakara Health Institute, P.O. Box 53, Ifakara, Tanzania

Full list of author information is available at the end of the article treated nets (ITNs), which are perhaps the best-evaluated and most cost-effective intervention for large-scale application [3-7]. The distribution programmes used in different countries have been as diverse as they have been numerous; but the goal to increase the coverage of both nets and insecticide levels has been common to all. In recent years, a number of success stories have emerged and the incidence of malaria has begun to decline in many regions of Africa [5-7]. 
The protective efficacy of ITNs results from both the physical barrier and the insecticidal action of the net. While it is intuitively clear that ITNs provide protection to individual users, what is less obvious is the impact of widespread ITN use at the community level. ITNs are able to reduce the density, feeding frequency and survival of mosquitoes [8-11] and wide-scale use can mediate protection of all community members, including the vulnerable portion without a bed net [12-15]. With moderate ITN coverage of the population, the 'mass effect' is at least as important as the personal protection provided to the user $[12,14,16]$. On the other hand, it has been suggested that ITN use could increase malaria risk for unprotected people by diverting mosquitoes away from users and concentrating their host-seeking efforts upon them $[9,17,18]$. Although theoretically possible, field studies have demonstrated that the beneficial impacts on malaria transmission outweigh any such inequitable biting burden for the unprotected $[8,14,19,20]$.

The current study is a retrospective analysis examining the impact of introducing a longer-lasting insecticide treatment into a setting with pre-existing high coverage of largely untreated nets. Two study villages in rural Tanzania experienced year-round, hyperendemic malaria transmission in the 1990s [21]. By the early 2000s, high coverage of untreated nets was achieved using a costsharing scheme for subsidisation and promotion [22]. More recently, national-scale subsidisation programmes co-packaged longer-lasting insecticide treatment kits with all bed nets manufactured in Tanzania and promoted their use from 2004 onwards [23,24]. The current study investigated whether the treatment of bed nets with longer-lasting insecticide produced any further impact on the intensity of malaria transmission beyond the 4.2-fold reduction observed from the use of untreated nets alone [22]. In order to examine changes in the entomologic inoculation rate (EIR) and the biodemographic profile of vector mosquitoes, their biting-density, sporozoite prevalence and survival was estimated in these same two villages throughout 2008. Results were compared with data collected from the same villages during 1990-94 before bed net use was common and during 2001-03 after high coverage of untreated bed nets had been achieved.

\section{Methods}

\section{Study area}

The study was conducted in Namawala and Idete villages, located in the Kilombero Valley $\left(8.1^{\circ} \mathrm{S}\right.$ and $\left.36.6^{\circ} \mathrm{E}\right)$ in south-eastern Tanzania (Figure 1). These communities experience hyper endemic malaria transmission [25], mostly transmitted by large populations of mosquitoes from the Anopheles gambiae sensu lato complex (Diptera: Culicidae) [26,27]. In this area, this species complex is represented by two morphologically identical, but behav-

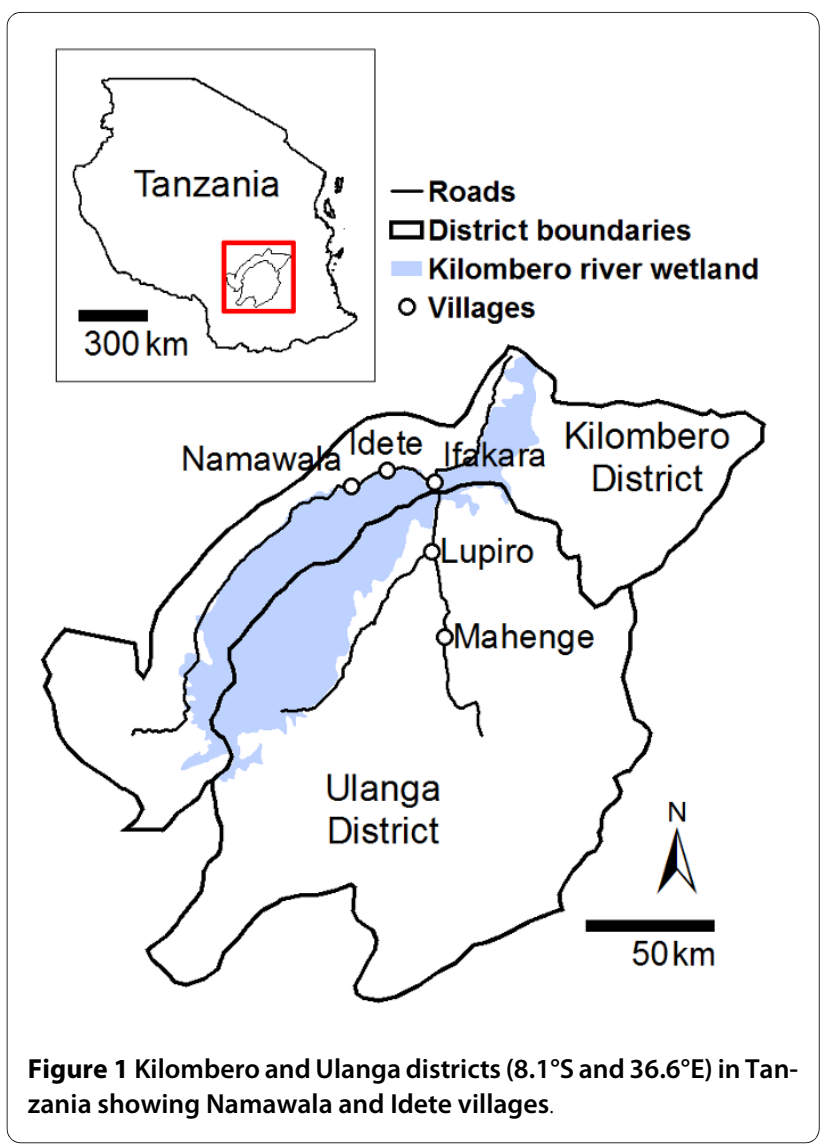

iourally distinctive, sibling species: A. gambiae sensu stricto (hereafter referred to as A. gambiae) and Anopheles arabiensis. A third, locally important vector species is Anopheles funestus. The ecosystem is dominated by a low lying river valley, $150 \mathrm{~km}$ long and up to $40 \mathrm{~km}$ wide, which is inter-dispersed with villages and rice farms. Annual flooding occurs during the rainy season (December - May) when large tracts of aquatic habitat suitable for immature mosquitoes are formed.

The epidemiology of malaria in the study villages has been well characterised over the past 15 years [e.g. [21,22,28-34]. Extremely high transmission intensities were recorded during the 1990s [21]. Since 1997, various cost-sharing schemes for subsidizing and promoting bed nets, as well as home insecticide treatment kits have been implemented in an effort to alleviate the malaria burden. The crux of the various programmes has been the generic branding of recommended nets and insecticides products which were sold in line with a price-fixing scheme that reflected a public subsidy (34\% of retail value at US \$5). To improve access to vulnerable pregnant women and infants, a further subsidy ( $17 \%$ of retail value) was provided through the use of a voucher scheme. The pregnant women and mothers of young children who attended antenatal or immunisation clinics were entitled to a discount voucher. 
The initial pilot programme, KINET, distributed bed nets within the Kilombero Valley and achieved remarkably high bed net coverage of all community members [16,22,25,35-37]. Although all KINET distributed bed nets were pre-treated with $20 \mathrm{mg} / \mathrm{m}^{2}$ deltamethrin [37], by 2001 , insecticide levels had fallen below $5 \%$ and most nets were in poor condition containing many holes $[22,38]$. Various national-scale distribution programmes have been implemented, commencing with PSI's Social Marketing of Insecticide Treated Nets (SMITN) programme which was run at a regional-scale during 19982000 and a national-scale during 2000-02 and promoted the use of nets and standard insecticide treatment kits (KO Tab, Icon and Fendona). The sequential programme was SMARTNET from 2002, which the Tanzanian National Voucher Scheme (TNVS) was built upon in 2004. SMARTNET ensured that all bed nets manufactured in Tanzania were co-packaged with longer-lasting insecticide treatment kits, which were registered for use from 2004 onwards (Initially: KO Tab 123, target dose: 25 mg deltamethrin $/ \mathrm{m}^{2}$ [39,40]; and from 2008: Icon ${ }^{\circ}$ MAXX, target dose: $50 \mathrm{mg}$ lambda-cyhalothrin/ $\mathrm{m}^{2}$ [41]).

\section{Experimental design}

In each village, 72 households were randomly selected for mosquito collection from the household list of the Ifakara Health Institute (IHI) Demographic Surveillance System (DSS) [25]. Each house was visited once a month (6 houses/day, 4 days/week and 3 weeks/month) over a period of 12 months (January to December 2008). Mosquitoes were collected inside houses using one CDC light trap that was placed beside a person sleeping underneath a bed net and left to run for 12 hours $(7 \mathrm{pm}-7 \mathrm{am})$ [42]. The light trap, fitted with an incandescent bulb, was placed $1-1.5 \mathrm{~m}$ above the floor and close to the feet of a bed net occupant. The bed net provided to the participating households was a new long-lasting insecticidal bed net (Olyset, A to Z Textile Mills Ltd., Tanzania). Although permethrin-treated bed nets exhibit modest excito-repellency, they have surprising little effect on the relative efficiency of light traps when compared with untreated bed nets $[22,43]$.

\section{Mosquito sampling and processing}

After each night of trapping, all mosquitoes were morphologically identified to sex and species then visually classified as being unfed, partially fed, fully fed or gravid $[27,44]$. Throughout the study, sub-samples of up to 9 individual mosquitoes were taken from each trap to determine parity status, sporozoite infection and sibling species identity. Mosquito survival was assessed using ovarian dissection for parity (parous versus nulliparous) [45], sporozoite infection was determined using ELISA [46] and the sibling species identity of the A. gambiae complex specimens were determined using PCR [47]. Prior to molecular analysis, individual mosquitoes were stored at $-20^{\circ} \mathrm{C}$ in micro centrifuge tubes containing a small amount of silica drying agent separated from the mosquito by a thin layer of cotton.

\section{Housing and climatic conditions}

The physical structure and size of eave openings for each randomly selected house was recorded directly. The use of bed nets and cattle ownership was estimated by the IHI DSS [25] during an annual survey of all households in the study villages. Each household head was asked: 1) how many people slept in the house, 2) how many people slept under a bed net the previous night, 3) how many bed nets the household had, 4) how many bed nets were treated, 5) in which month and year was the insecticide applied to each treated bed net and 6) how many head of cattle does the household own.

Rainfall data was collected on the nearby Kilombero Agricultural Training and Research Institute $(<12 \mathrm{~km}$ from Idete village). The hourly variation in temperature was recorded using a data logger (Tinytag TV-1500, Gemini Data Logger, UK) placed inside a local house in nearby Lupiro village [22].

\section{Statistical analysis}

Indoor mosquito sampling with CDC light traps is considered to be proportionally representative of true adult exposure $[22,42,48,49]$ so the biting rate (B) was not adjusted for the number of household inhabitants. To account for the lower efficiency of CDC light traps relative to human landing catch, which we consider to be equivalent to the exposure of an unprotected person lacking a net, the biting rate was calculated by dividing the number of mosquitoes caught by species-specific relative efficiency, being 0.30 for the $A$. gambiae complex, 0.68 for A. funestus and 0.59 for Culex spp. [22].

The annual EIR was calculated using the equation: EIR $=\mathrm{S} \times \mathrm{B} \times 365[1,2,21,22]$. Where, $\mathrm{S}$ (sporozoite prevalence $)=$ no. of sporozoite positive mosquitoes/no. of mosquitoes tested, and B (biting rate) $=$ no. of mosquitoes collected/(no. of trap nights $\times$ species-specific relative efficiency). The biting rate was calculated as an absolute mean opposed to the William's mean [33]. This approach provides a more realistic representation of the true total exposure of humans to malaria infection, as the majority of transmission events are due to a fraction of vectors that are commonly associated with high densities in overdispersed data [50,51].

The above approach is consistent with previous surveys of these villages allowing these data to be directly compared with previous estimates $[21,22,30,33]$. Comparable $\mathrm{S}, \mathrm{B}$ and EIR values were available from previous surveys in 1990-94 [22,29-34] and 2001-03 [22]. Each sampling 
period analysed represented a different phase of bed net coverage: 1990-94 preceded any substantive uptake of bed nets in this area [52] while 2001-03 followed a longterm programme of bed net promotion resulting in widescale use of untreated nets [22] and 2008 saw significant uptake of longer-lasting insecticide treatment kits as a result of national-scale efforts to promote them. Bed net coverage was calculated as the proportion of people sleeping under a bed net on the previous night. The yes/ no question asking if a bed net had even been treated was answered by all of the respondents, but only some of the positive respondents were able to delineate the timeframe for bed net treatment. As such, the proportion of treated bed nets was estimated by weighting the proportion of bed nets that had ever been treated by the proportion that were treated within the past 12 months.

The temporal change in annual village-level S, B, EIR, proportion parous and A. gambiae complex sibling species composition was analysed using generalised linear models (GLMs) with a categorical explanatory variable for study period. For the response variables B and EIR, the GLM used a negative binomial distribution and a log link function. For the variables $\mathrm{S}$, proportion parous and sibling species composition, the GLM used a binomial distribution and a logit link function. For these parameters, comparing annual village-level means over entire calendar-years averaged out short term temporal and spatial heterogeneity and thereby the analysis focused on long-term changes in these entomological parameters. As sporozoite prevalence is a property of entire communities rather than individual sampled houses [53], the villagelevel was considered to be the experimental unit $(n=2)$ for which B and $\mathrm{S}$ were both estimated as means of all samples from all houses over the entire year.

The construction of houses is known to influence the indoor densities of mosquitoes [54,55] so an additional analysis was conducted to examine this effect at the household level. The effect of closing eaves on the annual biting rate of Anopheline mosquitoes (B) for 2008 was analysed using a generalised linear mixed model (GLMM) [56] with eaves as a fixed factor and household and month as a random factor to account for repeated sampling. This GLMM model used a negative binomial distribution and a log link function. All analyses were conducted using the $R$ package V2.9.1.

\section{Ethics}

Ethical approval for the study was obtained from the IHI Institutional Review Board (IHRDC/IRB/No. A-32) and the Medical Research Coordination Committee of the National Institute for Medical Research (NIMR/HQ/ R.8a/Vol. IX/764) in Tanzania. When the study commenced, permission was obtained from each household owner who was informed about the potential risks and benefits of participation both orally and via provision of a written pamphlet. After consenting, the household head signed an informed consent form stating their willingness to participate in the study.

\section{Results}

During the 12 month survey 1,648 CDC light trap nights of sampling were conducted. A total of 97,437 female mosquitoes were caught, of which $98.5 \%$ were unfed and thus considered to have been mostly caught in the act of host-seeking. Of these mosquitoes, $30.9 \%$ were $\mathrm{A}$. gambiae complex $(n=30,111)$ comprising $85.8 \%$ A. arabiensis and $14.2 \%$ A. gambiae senso stricto $(n=2,924$ PCR amplifications). The remaining mosquitoes were $2.0 \%$ A. funestus $(n=1,950), 62.0 \%$ Culex spp $(n=60,442), 2.4 \%$ Mansonia spp $(n=2,302)$ and $2.7 \%$ other species including Aedes and Coquillettidia spp $(n=2,605)$.

The density of mosquitoes was temporally and spatially heterogeneous with the bulk of the mosquitoes (97.4\%) being caught between January and May. During this time there were multiple short-term peaks of mosquito emergence that occurred after rainfall (Figure 2). Members of the A. gambiae complex dominated the biting burden while A. funestus contributed to only $3 \%$ of the total Anopheles bites occurring in these two villages (Table 1).

The sporozoite prevalence of A. funestus (1.71\% infected, $n=527)$ and A. gambiae (1.18\% infected, $n=$ 507) were not different $\left(\mathrm{X}^{2}=0.197, p=0.656\right)$. Whereas, the sporozoite rate for $A$. arabiensis (0.16\% infected, $n=$ $3,116)$ was nearly 5 -fold lower than both $A$. funestus $\left(\mathrm{X}^{2}=\right.$ $24.29, p<0.0001)$ and A. gambiae $\left(\chi^{2}=11.88, p=0.0005\right)$. There was no difference in prevalence between villages for any of the species (A. gambiae complex: $\mathrm{X}^{2}=0.57, p=$ 0.45; A. funestus: $\mathrm{X}^{2}=2.28, p=0.13$ ).

The intensity of transmission experienced by unprotected people without a bed net provides the most direct indicator of community level transmission and protection. Overall, the EIR for non-users of bed nets was 81.9 infectious bites per person per year (ib/p/y, Table 1). Eighty-six percent of malaria transmission was attributable to the A. gambiae complex and $14 \%$ to A. funestus, with the majority of transmission (90\%) occurring between January and May. Malaria transmission intensity was approximately 2 -fold higher in Namawala than Idete, due to the high Anopheline biting rate in Namawala village.

Similar entomological surveys using light traps were conducted in the same villages between 1990 and 1994 (before wide-spread bed net use) and again between 2001 and 2003 (after high coverage of untreated nets had been achieved), allowing a comparison of current malaria transmission intensities with historical rates. In 2008, bed net coverage levels were extremely high with $91.5 \%$ of the population sleeping under a net the previous night and 

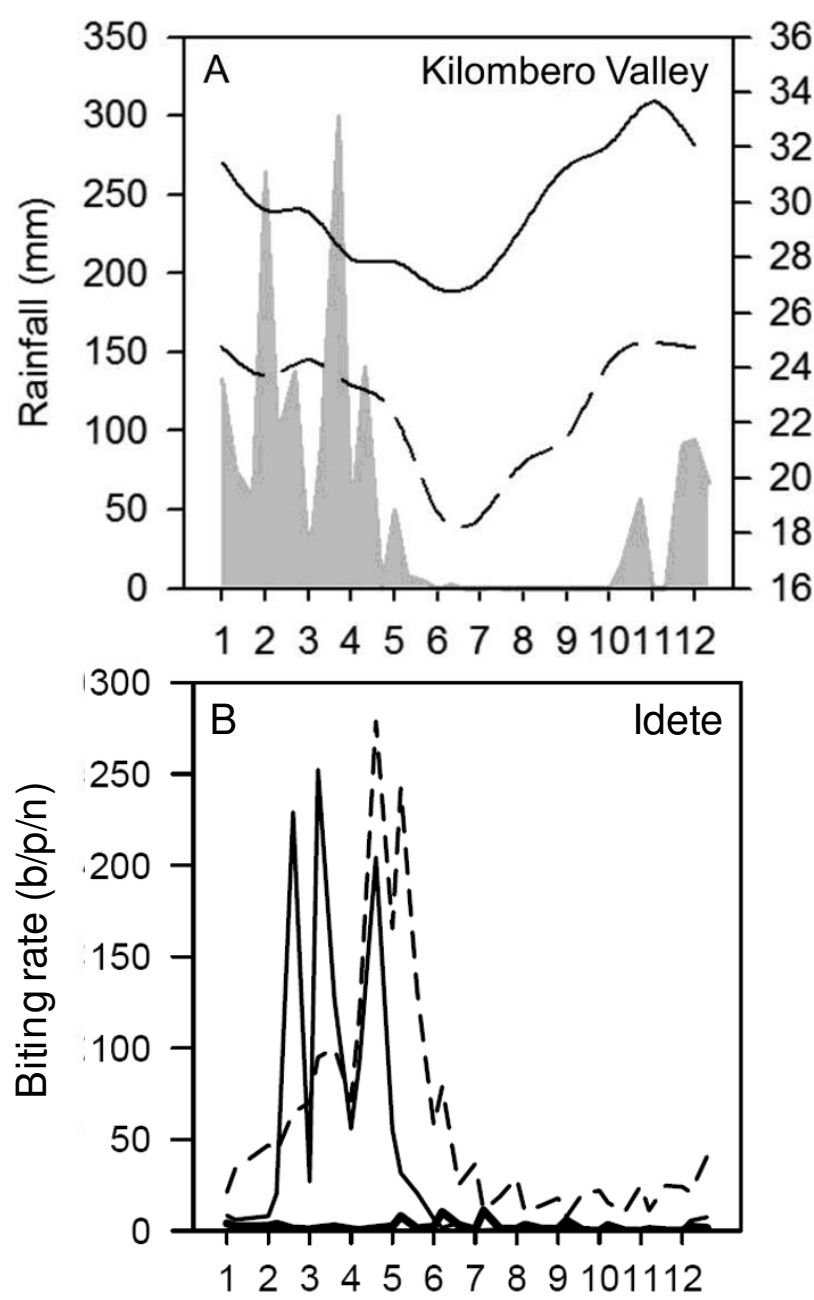

- A. gambiae complex

A. funestus

- - Culex spp.

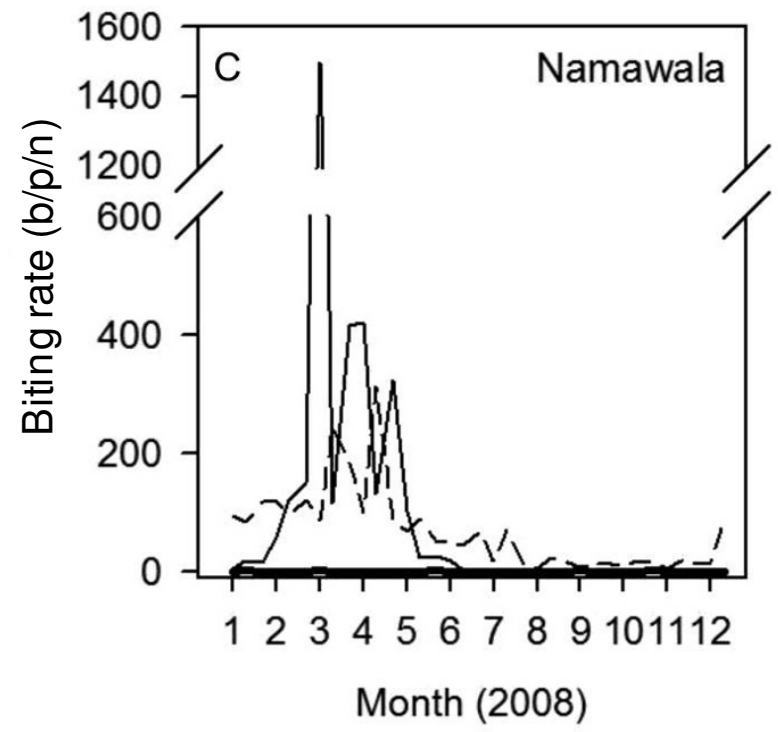

\section{A. gambiae complex}

A. funestus

- - Culex spp.

Figure 2 Weekly rainfall and temperature throughout the Kilombero Valley (A) and nightly biting rate of mosquitoes for Idete (B) and Namawala (C) estimated using the mean weekly CDC light trap catch adjusted by dividing by species-specific relative efficiency of $0.3,0.68$ and 0.59 for Anopheles gambiae complex, A. funestus and Culex spp. respectively [see [22]]. 
Table 1: The estimated malaria transmission intensity attributable to the Anopheles gambiae complex and Anopheles funestus, computed for each village separately and the $\mathbf{2 0 0 8}$ overall average

\begin{tabular}{|c|c|c|c|}
\hline Species & Idete & Namawala & Overall \\
\hline \multicolumn{4}{|l|}{ Sporozoite prevalence (S; \%) } \\
\hline A. gambiae complex & 0.22 & 0.33 & 0.32 \\
\hline No. tested by ELISA & 1,858 & 3,148 & 5,006 \\
\hline A. funestus & 2.13 & $<0.09$ & 1.71 \\
\hline No. tested by ELISA & 422 & 105 & 527 \\
\hline \multicolumn{4}{|l|}{ Biting rate $(B ; b / p / n)$} \\
\hline A. gambiae complex & 33.51 & 89.66 & 60.90 \\
\hline A. funestus & 2.40 & 1.05 & 1.74 \\
\hline No. of trap nights & 916 & 732 & 1,648 \\
\hline \multicolumn{4}{|c|}{ Entomological inoculation rate (EIR; ib/p/y) } \\
\hline A. gambiae complex & 26.3 & 124.8 & 71.1 \\
\hline A. funestus & 18.7 & 0.3 & 10.8 \\
\hline Total & 45.0 & 125.1 & 81.9 \\
\hline \multicolumn{4}{|l|}{ Proportion parous } \\
\hline A. gambiae complex & 0.45 & 0.54 & 0.51 \\
\hline No. dissected & 353 & 736 & 1,089 \\
\hline \multicolumn{4}{|c|}{ A. gambiae complex sibling species proportion } \\
\hline A. arabiensis & 0.87 & 0.84 & 0.86 \\
\hline A. gambiae & 0.12 & 0.15 & 0.14 \\
\hline No. PCR amplifications & 1,481 & 2,599 & 4,080 \\
\hline \multicolumn{4}{|l|}{ Bed net usage (\%)a } \\
\hline Untreated & 41.0 & 47.3 & 44.8 \\
\hline Treated & 47.0 & 46.6 & 46.8 \\
\hline Overall & 87.9 & 94.0 & 91.5 \\
\hline No. of bed net users & 4,112 & 6,551 & 10,663 \\
\hline
\end{tabular}

$\mathrm{S}=$ no. of sporozoite positive mosquitoes/no. of mosquitoes tested

$\mathrm{B}=$ no. of mosquitoes collected/no. of trap nights/calibration factor of 0.30 for $A$. gambiae complex and 0.68 for $A$. funestus; and EIR $=S \times B \times$ 365

a Calculated as the percentage of people who slept under a bed net the previous night; bed nets were considered to be treated if insecticide had been applied in the previous 12 months

$46.8 \%$ sleeping under an ITN. Since 1990-94 there has been an 8.4-fold reduction of the sporozoite prevalence of the A. gambiae complex, but surprisingly little change in the sporozoite prevalence of $A$. funestus (Table 2, Figure 3 ). The biting rate of the A. gambiae complex has reduced by 2.5 -fold and for A. funestus by 13 -fold. Between 199094 and 2001-03 the EIR was reduced by 4.2-fold [22] and between 2001-03 and 2008 by a further 4.6-fold. Thus, compared with the exposure of non-users in 1990-94 by 2008 there had been an 18-fold (95\%) overall community level reduction in transmission intensity for non-users of bed nets. Considering that users of bed nets receive both personal and community level protection, the exposure of bed net users was calculated by adjusting for personal protection from $40 \%$ of bites for an untreated net user and $70 \%$ of bites for an ITN user [57]. As such, users of untreated nets probably experienced a 30-fold (97\%) reduction and users of ITNs experienced a 60-fold (98\%) reduction. In 2008, the mean EIR of an average community member calculated as an average weighted according to the recorded bed net use (Table 1 ) was $33.9 \mathrm{ib} / \mathrm{p} / \mathrm{y}$.

Temporal changes in malaria transmission intensity may be mediated by changes in a range of fundamental biological determinants of the mosquito population including the age distribution or species composition of the mosquito populations. Wide-spread bed net use appears to have mediated a drop in vector survival rates which was subsequently followed by population decline 
Table 2: Differences in the historical and recent estimates of sporozoite prevalence (S), biting rate (B) and entomological inoculation rate (EIR) for the Anopheles gambiae complex, Anopheles funestus and overall

\begin{tabular}{|c|c|c|}
\hline Year & $\mathrm{OR}^{\mathrm{a}}$ or $\mathbf{R R}^{\mathbf{b}}[95 \% \mathrm{Cl}]$ & $p$ value \\
\hline \multicolumn{3}{|c|}{ Sporozoite prevalence $(S)^{a}$} \\
\hline \multicolumn{3}{|c|}{ A. gambiae complex } \\
\hline 1990-1994c & 1.00 & NA \\
\hline $2001-2003^{d}$ & $0.450[0.392,0.518]$ & $<0.0001$ \\
\hline 2008 & $0.128[0.075,0.218]$ & $<0.0001$ \\
\hline \multicolumn{3}{|l|}{ A. funestus } \\
\hline $1990-1994^{c}$ & 1.00 & NA \\
\hline $2001-2003^{d}$ & $0.716[0.609,0.842]$ & $<0.0001$ \\
\hline 2008 & $0.735[0.377,1.432]$ & 0.366 \\
\hline \multicolumn{3}{|l|}{ Overall } \\
\hline 1990-1994c & 1.00 & NA \\
\hline $2001-2003^{d}$ & $0.530[0.477,0.589]$ & $<0.0001$ \\
\hline 2008 & $0.185[0.122,0.281]$ & $<0.0001$ \\
\hline \multicolumn{3}{|c|}{ Bites per person per night $(B)^{b}$} \\
\hline \multicolumn{3}{|c|}{ A. gambiae complex } \\
\hline $1990-1994 c$ & 1.00 & NA \\
\hline $2001-2003^{d}$ & $0.486[0.241,0.983]$ & 0.044 \\
\hline 2008 & $0.405[0.200,0.821]$ & 0.012 \\
\hline \multicolumn{3}{|l|}{ A. funestus } \\
\hline $1990-1994^{c}$ & 1.00 & NA \\
\hline $2001-2003^{d}$ & $0.396[0.233,0.673]$ & 0.0006 \\
\hline 2008 & $0.072[0.024,0.214]$ & $<0.0001$ \\
\hline \multicolumn{3}{|l|}{ Overall } \\
\hline $1990-1994^{c}$ & 1.00 & NA \\
\hline $2001-2003^{d}$ & $0.474[0.250,0.899]$ & 0.022 \\
\hline 2008 & $0.359[0.188,0.686]$ & 0.0019 \\
\hline \multicolumn{3}{|c|}{ Entomological inoculation rate (EIR) } \\
\hline \multicolumn{3}{|c|}{ A. gambiae complex } \\
\hline 1990-1994c & 1.00 & NA \\
\hline $2001-2003^{d}$ & $0.214[0.075,0.612]$ & 0.004 \\
\hline 2008 & $0.061[0.021,0.176]$ & $<0.0001$ \\
\hline \multicolumn{3}{|l|}{ A. funestus } \\
\hline $1990-1994 c$ & 1.00 & NA \\
\hline $2001-2003^{d}$ & $0.241[0.052,1.100]$ & 0.066 \\
\hline 2008 & $0.039[0.008,0.188]$ & $<0.0001$ \\
\hline \multicolumn{3}{|l|}{ Overall } \\
\hline 1990-1994c & 1.00 & NA \\
\hline
\end{tabular}


Table 2: Differences in the historical and recent estimates of sporozoite prevalence (S), biting rate (B) and entomological inoculation rate (EIR) for the Anopheles gambiae complex, Anopheles funestus and overall (Continued)

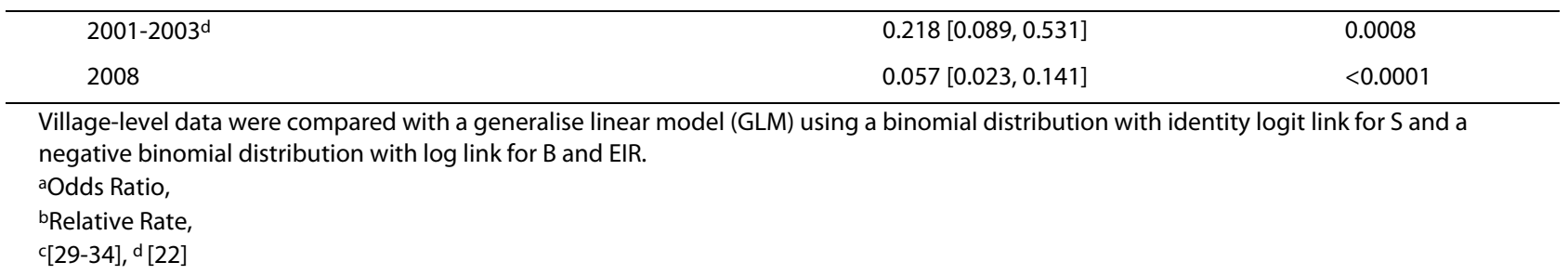

of highly anthropophagic species particularly once insecticide treatment became common. Overall, the proportion of parous mosquitoes has decreased from 0.62 in 1990-94 [30,31] to 0.43 in 2008 (Table 3). The proportion of A. gambiae among the complex decreased from 0.46 in 1990-94 [29,30,34] to 0.14 in 2008 (Table 3). During the initial six years of bed net use (commencing 1997) the parity rate of the mosquitoes declined, but at this time the proportions of A. gambiae and A. arabiensis remained fairly constant. By the time insecticide coverage had increased in 2008, additional reductions in the parity rate were very modest, but the population density of A. gambiae declined relative to that of A. arabiensis.

The widespread use of ITNs placed a high level of stress on vectors that are highly endophagic and dependent on humans for blood [58], mediating a 79\% reduction in $A$. gambiae density $(69.9 \mathrm{~b} / \mathrm{p} / \mathrm{n}$ in $1990-94$ versus $8.4 \mathrm{~b} / \mathrm{p} / \mathrm{n}$ in 2008). The reduction in $A$. gambiae density was presumably mediated by reduced survival. The proportion of parous $A$. gambiae, was very low at $0.39(n=76)$. On the other hand, bed net use has not had the same level of impact on the exophagic, zoophagic $A$. arabiensis, the density of which was only reduced by $38 \%$ since $1990-94$ $(82.0 \mathrm{~b} / \mathrm{p} / \mathrm{n}$ in $1990-94$ versus $51.6 \mathrm{~b} / \mathrm{p} / \mathrm{n}$ in 2008$)$. The proportion of parous $A$. arabiensis was $0.45(n=466)$ and higher than $A$. gambiae, but the difference in parity between the sibling species was not significant $\left(\chi^{2}=\right.$ $0.730, p=0.393)$. The change in the composition of the $A$. gambiae complex resulted in $39 \%$ of transmission being attributable to A. arabiensis (calculated by adjusting both the sporozoite prevalence and biting rate), with $47 \%$ due to $A$. gambiae and $14 \%$ due to A. funestus. For the previous sample periods, we were unable to calculate the proportion of transmission attributable to the sibling species of the A. gambiae complex because species-specific sporozoite prevalence data was unavailable.

When interpreting the decline in malaria transmission over time, it is important to acknowledge other factors, such as increases in population density $[59,60]$ or environmental changes [61-63], which can contribute to declines in malaria transmission. The population has increased dramatically from $\sim 1,000$ people per village in 1990-94 [52] to 4,673 people in Idete and 6,970 in
Namawala in 2008. In 1990-94 there was an absence of cattle in the villages [52], but by 2008 there 306 head of cattle in Idete and 6,667 in Namawala. House construction may affect mosquito densities and consistent with published literature $[54,55]$ the biting rate of the A. gambiae complex (Relative Rate (RR) [95\% Confidence Intervals $(\mathrm{CI})]=0.689[0.539,0.882], p=0.005)$ and $A$. funestus ( $\mathrm{RR}[95 \% \mathrm{CI}]=0.858[0.776,0.948], p=0.005)$ was lower in houses with closed eaves. The randomly selected houses during 2008 were built from clay-fired bricks $(58 \%)$, mud $(38 \%)$, grass thatch $(2 \%)$ or clay unfired bricks (2\%), with roofing of grass thatch $(53 \%)$ or corrugated iron (47\%). The majority (71\%) had open eaves with a mean eave size of $14.6 \pm 0.7 \mathrm{~cm}$. In 1990-94, all of the houses were constructed from mud walls with thatched roofs [52], but importantly the portion of houses with open eaves was similar $[54,55]$. Although it rained heavily during 2008 (Figure 2a; total annual rainfall 2,401 mm) this would only have served to inflate the observed EIR values and provides further support to the results.

\section{Discussion}

The study showed that in a setting where coverage of untreated bed nets was already high, the addition of longer-lasting insecticide treatment of bed nets was associated with a further 4.6-fold reduction in malaria transmission. This was in addition to the 4.2-fold reduction already associated with the use of untreated nets alone. Overall, an 18-fold reduction in transmission relative to the historical norms was recorded, demonstrating that combining the impacts of bed nets and insecticide, at high coverage rates, has a multiplicative effect along a linear scale or additive along a log scale $[64,65]$.

The bed net distribution programmes which this area has been included in (the local pilot KINET and the various national-scale programmes) were based on a costsharing scheme that supported a commercial ITN distribution system combined with targeted subsidies for the most vulnerable community members. The programme is cost-effective [23] and was successful at achieving 91.5\% use of bed nets by all community members, rather than just target groups, by 2008 (Table 1). Further, $46.8 \%$ of people slept under bed nets that were treated with lon- 

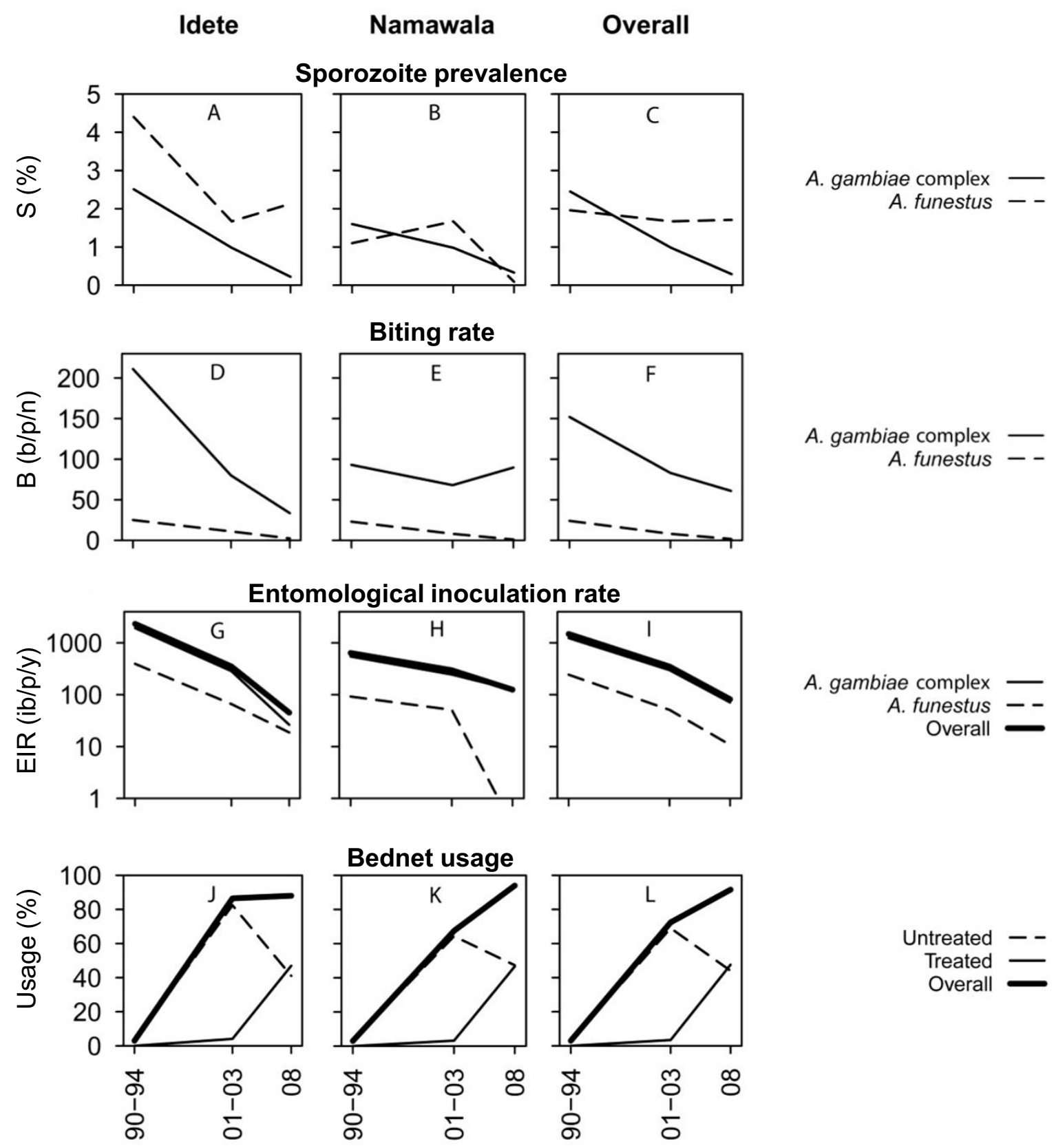

Year

Figure 3 Graphical comparison of the historical and recent estimates of sporozoite prevalence (A-C), biting rate (D-F) and entomological inoculation rate (G-H) for Anopheles gambiae complex and Anopheles funestus and overall. The corresponding bed net usage recorded for the same areas and time periods ( $\mathrm{J}-\mathrm{L}$ ) demonstrate the negative association between bed net usage and EIR. Note: Data for 1990-94 was from [29-34,52] and 2001-03 was from [22]. The B and EIR values for 1990-94 were recalculated by [22].

ger-lasting insecticide within the last 12 months. It is important to note that the use of bed nets in the study villages is higher than the national average (40.8\%) [66] since coverage was high before the national-scale programmes commenced.

The ITN coverage has reached the theoretical threshold $(35-65 \%)$ required to mediate community level sup- 
Table 3: The parity and sibling species composition of the Anopheles gambiae complex populations in averaged across Idete and Namawala villages

\begin{tabular}{|c|c|c|c|}
\hline Year & Proportion (n/total) & Odds ratio $[95 \% \mathrm{CI}]$ & $p$ value \\
\hline \multicolumn{4}{|l|}{ Parity } \\
\hline 1990-1994a & $0.62(9,690 / 15,541)$ & 1.00 & NA \\
\hline $2001-2003^{b}$ & $0.47(2,995 / 6,372)$ & $0.535[0.504,0.568]$ & $<0.0001$ \\
\hline 2008 & $0.51(448 / 641)$ & $0.422[0.372,0.478]$ & $<0.0001$ \\
\hline \multicolumn{4}{|c|}{ Sibling A. gambiae sensu stricto } \\
\hline 1990-1994a & $0.46(101 / 220)$ & 1.00 & NA \\
\hline $2001-2003^{b}$ & $0.38(60 / 157)$ & $0.812[0.532,1.240]$ & 0.336 \\
\hline 2008 & $0.14(584 / 4080)$ & $0.196[0.148,0.260]$ & $<0.0001$ \\
\hline
\end{tabular}

$\mathrm{a}[29-34], \mathrm{b}[22]$

pression of malaria mortality and morbidity [12]. The community-wide entomological impacts observed are consistent with epidemiological outputs in Idete village, where ITN use protected non-users from anaemia and splenomegaly [16]. Similarly, previous trials in sub-Saharan Africa have demonstrated a reduction in malaria mortality and/or morbidity of unprotected children who reside in or near clusters of households with high ITN use $[14,15,19]$. This study reflects the impact of ITN use on transmission under programmatic conditions where distribution is uneven, with protected and unprotected people inter-dispersed throughout the villages.

A substantial reduction in the intensity of malaria transmission, or EIR, was most likely associated with the ability of both untreated and treated nets to confer protection to the wider community, not just individual users. The EIR is the product of mosquito biting-densities (B) and the sporozoite rates $(\mathrm{S})$ and both were reduced in the survey villages. The estimate of a reduced EIR by $95 \%$ for non-users is similar to previous estimates $(90-94 \%)$ for ITN trials in Africa $[67,68]$. The most obvious mechanisms through which ITNs could have reduced vector density and survival are mortality when attacking an occupant of a ITN [8,67-69] and longer and more hazardous searches for blood-meals [70]. Regarding the sporozoite prevalence of the A. gambiae complex, this may have declined as a result of the reduced proportion of $A$. gambiae relative to $A$. arabiensis, since the sporozoite prevalence of $A$. arabiensis is consistently lower than that of A. gambiae. Other mechanisms that may also have contributed are the diversion of mosquitoes to alternative hosts $[20,71,72]$, reduced feeding frequency $[9,73]$ or reduced survival $[67,68]$. Surprisingly, the sporozoite prevalence of $A$. funestus did not change over time and in 2008 the sporozoite prevalence of $A$. gambiae was not different to A. funestus, suggesting that the sporozoite prev- alence of A. gambiae had not changed with time either. The discrepancy between reduced mosquito survival corresponding with minimal impact on sporozoite prevalence may possibly be due to manipulation of infected mosquitoes by malaria parasites to extend their lifespan and increased feeding frequency [74].

With only two village-scale experimental unit replicates tracked through three time periods, the greatest limitation of this study is that it is essentially descriptive and observational. This study is a retrospective analysis of non-experimental data and, therefore, represents plausible rather than probable evidence [75] of community level suppression of transmission. It was not possible to contrast the results of this study with a control site where bed nets remained untreated, since preventing people from accessing ITNs would have been ethically inappropriate. Nonetheless, clear changes to the EIR and the biodemographic profile of the vector species have been associated with the introduction of bed nets and insecticide treatments.

The biodemographic profile of mosquito populations may have also been altered by changes in land-use or landscape ecology [61-63]. With time, the population and geographic size of the villages has increased. During this process, some of the remote farming regions from 199094 have been urbanized. Regardless the general layout of the villages remains similar with a densely populated town centre and many people still residing in rural farming regions on the outskirts. During each study period, mosquito sampling was conducted in both farming and town houses, accounting for some of the biases caused by changes in landscape ecology over time. The highest densities of mosquitoes were captured in the farming regions where houses are constructed in close proximity to the larval habitats found in rice paddies. However, the observed reduction in EIR was much stronger than what 
would be expected due to changes in population size alone, as increases in population density can only mediate an equivalent reduction in transmission intensity $[59,60]$. Improvements in socio-economic status could also have contributed to the decreased risk of malaria transmission [76-78]. In general the socio-economic status of the villages has improved since 1990-94, as indicated by changes in house construction, a commonly used proxy measurement [79].

The introduction of bed nets, enforced with insecticides, had a stronger impact on the density and survival of the anthropophagic, endophagic A. gambiae than its zoophagic, exophagic sibling species $A$. arabiensis. The change in the proportional biting of the sibling species was not attributable to competitive displacement of $A$. gambiae by $A$. arabiensis [80], but merely a more severe reduction in A. gambiae density and survival. It is clear that the $A$. arabiensis population has been stressed by the use of ITNs, but this species may have adapted by either taking a higher portion of blood-meals from animal sources [81-83], or by biting earlier in the night when humans are outdoors and unprotected $[84,85]$. Similar shifts in sibling species composition due to selective pressure of domestic insecticide interventions were previously recorded for A. gambiae relative to $A$. arabiensis in Kenya [86,87] following sustained ITN use and for $A$. funestus relative to Anopheles rivulorum and/or Anopheles parensis in South Africa, Kenya and Tanzania following indoor-residual spraying $[88,89]$. Consequently, there is need for additional vector control tools that target exophagic, zoophagic vectors, such as A. arabiensis, to be integrated into existing malaria control programmes; for example zooprophylaxis [70], insecticide treated cattle [90], outdoor resting traps [91], or push-pull strategies [92].

\section{Conclusion}

Insecticide treatment of nets reduced the intensity of malaria transmission in addition to that achieved by the untreated nets alone. Overall, an 18-fold (95\%) community level reduction in transmission intensity was recorded for non-users of bed nets. These results clearly demonstrate that vector control in rural areas with high densities of mosquitoes is possible. The predominantly polyester-based net technologies currently used in these villages may be improved upon and further reductions are possible since the "catch up" programmes for free polyethylene-based long-lasting insecticidal bed net distribution commenced in late 2009. Impacts of insecticide-treated net use were most pronounced against the highly anthropophagic, endophagic primary vector, leading to a shift in the sibling species composition of the $A$. gambiae complex. Since almost $40 \%$ of transmission is now attributable to the exophagic, zoophagic $A$. arabien- sis, additional vector control tools that specifically target this cryptic sibling species need to be integrated into existing malaria control programmes.

\section{Competing interests}

The authors declare that they have no competing interests.

\section{Authors' contributions}

TLR designed the study, supervised the mosquito sampling protocol, performed the data analysis and wrote the first draft of the manuscript. DWL implemented the longitudinal mosquito sampling protocol and assisted with data entry and analysis. DM and BC performed the molecular analysis of mosquito samples. JK supervised all aspects of mosquito sampling during all three study periods. JDC, TAS and CL designed and managed the collection of data during the 2001-03 sampling period. MAM and RN coordinated the collection of demographic and bed net usage data. BK and WT contributed to the study design and interpretation of the results. GFK contributed to the study design, data analysis and interpretation and drafting of the manuscript. All authors have read and approved the final manuscript.

\section{Acknowledgements}

We thank the staff at the Ifakara Health Institute especially Peter Pazia, Daniel Lugiko, Nuru Nchimbi, Matrida Kideule and Cesilia Mchopa for technical assistance in conducting entomological surveillance and Bernard Liseki, Fransis Allen for assistance with molecular analysis. We thank the residents of Idete and Namawala village for their patience and cheerful cooperation in the many surveys conducted over the past 16 years, and the Kilombero Agricultural Training and Research Institute (KATRIN) for kindly supplying rainfall data. This work was funded by the Addessium Foundation (Reeuwijk, The Netherlands), the Bill and Melinda Gates Foundation (51431), the Swiss National Science Foundation (3270-059542) and a Research Career Development Fellowship (076806) awarded to GFK by the Wellcome Trust. The manuscript was improved by constructive comments from Jane E. Miller, Nick Brown and an anonymous reviewer.

\section{Author Details}

'Biomedical and Environmental Thematic Group, Ifakara Health Institute, P.O. Box 53, Ifakara, Tanzania, ${ }^{2}$ Department of Biological and Biomedical Sciences, Durham University, South Road, Durham, DH1 3LE, UK, Vector Group,

Liverpool School of Tropical Medicine, Pembroke Place, Liverpool, L3 5QA, UK, ${ }^{4}$ Department of Zoology and Marine Biology, University of Dar es Salaam, P.O. Box 35064, Dar es Salaam, Tanzania, 5DBL Centre for Health Research \& Development, 57 Thorvaldensvej, Fredriksberg -C, DK 1870, Denmark, ${ }^{6}$ Department of Public Health and Epidemiology, Swiss Tropical Institute, Socinstrasse 57, Basel, CH 4002, Switzerland, 7 Division of Infectious Diseases, Tropical Medicine \& AIDS Academic Medical Center, F4-217, Meibergdreef 9, 1105 AZ, Amsterdam, The Netherlands and 'Laboratory of Entomology, Wageningen University and Research Centre, P.O. Box 8031, 6700 EH, Wageningen, The Netherlands

Received: 17 November 2009 Accepted: 28 June 2010 Published: 28 June 2010

\section{References}

1. Beier JC, Killeen GF, Githure Jl: Short report: Entomologic inoculation rates and Plasmodium falciparum malaria prevalence in Africa. Am J Trop Med Hyg 1999, 61(1):109-113.

2. Smith DL, Dushoff J, Snow RW, Hay SI: The entomolgical inoculation rate and Plasmodium falciparum infection in African children. Nature 2005, 438:492-495.

3. Lengeler $\mathrm{C}$ : Insecticide-treated bednets and curtains for preventing malaria (Review). Cochrane Database Syst Rev 2004, 2:CD000363.

4. Noor AM, Mutheu JJ, Tatem AJ, Hay SI, Snow RW: Insecticide-treated net coverage in Africa: mapping progress in 2000-07. Lancet 2009, 373(9657):58-67.

5. Ceesay SJ, Casals-Pascual C, Erskine J, Anya SE, Duah NO, Fulford AJC, Sesay SSS, Abubakar I, Dunyo S, Sey O, et al.: Changes in malaria indices between 1999 and 2007 in The Gambia: a retrospective analysis. Lancet 2008, 372(9649):1545-1554. 
6. Bhattarai A, Ali AS, Kachur SP, Mårtensson A, Abbas AK, Khatib R, Almafazy Aw, Ramsan M, Rotllant G, Gerstenmaier JF, et al: Impact of artemisinin-based combination therapy and insecticide-treated nets on malaria burden in Zanzibar. PLoS Med 2007, 4(11):e309.

7. O'Meara WP, Bejon P, Mwangi TW, Okiro EA, Peshu N, Snow RW, Newton CRJC, Marsh K: Effect of a fall in malaria transmission on morbidity and mortality in Kilifi, Kenya. Lancet 2008, 372(9649):1555-1562.

8. Gimnig JE, Vulule JM, Lo TQ, Kamau L, Kolczak MS, Phillips-Howard PA, Mathenge EM, Ter Kuile FO, Nahlen BL, Hightower AW: Impact of permethrin-treated bed nets on the entomologic indicies in an area of intense year-round malaria transmission. Am J Trop Med Hyg 2003, 68(90040):16-22.

9. Lines JD, Myamba J, Curtis CF: Experimental hut trials of permethrinimpregnated mosquito nets and eave curtains against malaria vectors in Tanzania. Med Vet Entomol 1987, 1(1):37-51.

10. Miller JE, Lindsay SW, Armstrong JR: Experimental hut trials of bednets impregnated with synthetic pyrethroid or organophosphate insecticide for mosquito control in The Gambia. Med Vet Entomol 1991, 5(4):465-476.

11. Lindsay SW, Adiamah JH, Miller JE, Armstrong JRM: Pyrethroid-treated bednet effects on mosquitoes of the Anopheles gambiae complex in The Gambiae. Med Vet Entomol 1991, 5:477-483.

12. Killeen GF, Smith TA, Ferguson HM, Abdulla S, Mshinda H, Lengeler C, Kachur SP: Preventing childhood malaria in Africa by protecting adults from mosquitoes with insecticide treated-nets. PLoS Med 2007, 4(7):e229.

13. Maxwell CA, Msuya E, Sudi M, Njunwa KJ, Carneiro IA, Curtis CF: Effect of community-wide use of insecticide-treated nets for 3-4 years on malarial morbidity in Tanzania. Trop Med Int Health 2002, 7:1003-1008.

14. Hawley WA, Phillips-Howard PA, Ter Kuile FO, Terlouw DJ, Vulule JM, Ombok M, Nahlen BL, Gimnig JE, Kariuki SK, Kolczak MS: Communitywide effects of permethrin-treated bed nets on child mortality and malaria morbidity in Western Kenya. Am J Trop Med Hyg 2003, 68(90040):121-127.

15. Binka FN, Indome F, Smith T: Impact of spatial distribution of permethrin-impregnated bed nets on child mortality in rural northern Ghana. Am J Trop Med Hyg 1998, 59(1):80-85.

16. Abdulla S, Gemperli A, Mukasa O, Armstrong Schellenberg JRM, Lengeler C, Vounatsou P, Smith T: Spatial effects of the social marketing of insecticide-treated nets on malaria morbidity. Trop Med Int Health 2005, 10(1):11-18

17. Killeen GF, Smith TA: Exploring the contributions of bednets, cattle, insecticides and excito-repellency to malaria control: A deterministic model of mosquito host-seeking behaviour and mortality. Trans R SOC Trop Med Hyg 2007, 101:867-880.

18. Genton B, Hii J, Al-Yaman F, Paru R, Beck HP, Ginny M, Dagoro H, Lewis D, Alpers MP: The use of untreated bednets and malaria infection, morbidity and immunity. Ann Trop Med Parasitol 1994, 88(3):263-270.

19. Howard SC, Omumbo J, Nevill C, Some ES, Donnelly CA, Snow RW Evidence for a mass community effect of insecticide-treated bednets on the incidence of malaria on the Kenyan coast. Trans $R$ Soc Trop Med Hyg 2000, 94(4):357-360.

20. Hii JL, Smith T, Vounatsou P, Alexander N, Mai A, Ibam E, Alpers MP: Area effects of bednet use in a malaria-endemic area in Papua New Guinea. Trans R Soc Trop Med Hyg 2001, 95(1):7-13.

21. Smith T, Charlwood JD, Kihonda J, Mwankusye S, Billingsley P, Meuwissen J, Lyimo E, Takken W, Teuscher T, Tanner M: Absence of seasonal variation in malaria parasitaemia in an area of intense seasonal transmission. Acta Trop 1993, 54(1):55-72.

22. Killeen GF, Tami A, Kihonda J, Okumu FO, Kotas ME, Grundmann H, Kasigudi N, Ngonyani H, Mayagaya V, Nathan R, et al:: Cost-sharing strategies combining targeted public subsidies with private-sector delivery achieve high bednet coverage and reduced malaria transmission in Kilombero Valley, southern Tanzania. BMC Infect Dis 2007, 7:121

23. Mulligan JA, Yukich J, Hanson K: Costs and effects of the Tanzanian national voucher scheme for insecticide-treated nets. Malar J 2008, 7(1):32.

24. Magesa SM, Lengeler C, deSavigny D, Miller JE, Njau RJ, Kramer K, Kitua A, Mwita A: Creating an "enabling environment" for taking insecticide treated nets to national scale: the Tanzanian experience. Malar J 2005, $4: 32$.
25. Armstrong Schellenberg JRM, Abdulla S, Nathan R, Mukasa O, Marchant TJ, Kikumbih N, Mushi AK, Mponda H, Minja H, Mshinda H, et al.: Effect of large-scale social marketing of insecticide-treated nets on child survival in rural Tanzania. Lancet 2001, 357(9264):1241-1247.

26. White GB: Anopheles gambiae complex and disease transmission in Africa. Trans R Soc Trop Med Hyg 1974, 68(4):278-301.

27. Gillies MT, Coetzee M: A supplement to the Anophelinae of Africa south of the Sahara (Afrotropical region). Johannesburg: South African Institute for Medical Research; 1987.

28. Smith T, Charlwood JD, Takken W, Tanner M, Spiegelhalter DJ: Mapping the densities of malaria vectors within a single village. Acta Trop 1995, 59:1-18.

29. Charlwood JD, Kihonda J, Sama S, Billingsley PF, Hadji H, Verhave JP, Lyimo E, Luttikhuizen PC, Smith T: The rise and fall of Anopheles arabiensis (Diptera: Culicidae) in a Tanzanian village. Bull Entomol Res 1995, 85:37-44.

30. Charlwood JD, Smith T, Billingsley PF, Takken W, Lyimo E, Meuwissen J: Survival and infection probabilities of anthropophagic anopelines from an area of high prevalence of Plasmodium falciparum in humans. Bull Entomol Res 1997, 87:455-453.

31. Takken W, Charlwood JD, Billingsley PF, Gort G: Dispersal and survival of Anopheles funestus and A. gambiae s.l. (Diptera: Culicidae) during the rainy season in southeast Tanzania. Bull Entomol Res 1998, 88(5):561-566.

32. Smith T, Charlwood JD, Kitua AY, Masanja H, Mwankusye S, Alonso PL, Tanner M: Relationship of malaria morbidity with exposure to Plasmodium falciparum in young children in a highly endemic area. Am J Trop Med Hyg 1998, 59(2):252-257.

33. Charlwood JD, Smith T, Lyimo E, Kitua AY, Masanja H, Booth M, Alonso PL, Tanner M: Incidence of Plasmodium falciparum infection in infants in relation to exposure to sporozoite-infected anophelines. Am J Trop Med Hyg 1998, 59(2):243-251

34. Charlwood JD, Vij R, Billingsley PF: Dry season refugia of malariatransmitting mosquitoes in a dry savannah zone of east Africa. Am J Trop Med Hyg 2000, 62(6):726.

35. Abdulla S, Armstrong Schellenberg J, Nathan R, Mukasa O, Marchant T, Smith T, Tanner M, Lengeler C: Impact on malaria morbidity of a programme supplying insecticide treated nets in children aged under 2 years in Tanzania: community cross sectional study. BMJ 2001, 322(7281):270-273

36. Marchant T, Schellenberg JA, Edgar T, Nathan R, Abdulla S, Mukasa O, Mponda $\mathrm{H}$, Lengeler $\mathrm{C}$ : Socially marketed insecticide-treated nets improve malaria and anaemia in pregnancy in southern Tanzania. Trop Med Int Health 2002, 7(2):149-158.

37. Armstrong Schellenberg JRM, Abdulla S, Minja H, Nathan R, Mukasa O, Marchant T, Mponda H, Kikumbih N, Lyimo E, Manchester T, et al:: KINET: a social marketing programme of treated nets and net treatment for malaria control in Tanzania, with evaluation of child health and longterm survival. Trans R Soc Trop Med Hyg 1999, 93(3):225-231.

38. Erlanger TE, Enayati AA, Hemingway J, Mshinda H, Tami A, Lengeler C: Field issues related to effectiveness of insecticide-treated nets in Tanzania. Med Vet Entomol 2004, 18(2):153-160.

39. Oxborough RM, Weir V, Irish S, Kaur H, N'Guessan R, Boko P, Odjo A, Metonnou C, Yates A, Akogbeto M, et al.: Is K-O Tab 1-2-3 long lasting on non-polyester mosquito nets? Acta Trop 2009, 112(1):49-53.

40. Yates A, N'Guessan R, Kaur H, Akobéto M, Rowland M: Evaluation of KOTab 1-2-3 : a wash-resistant 'dip-it-yourself' insecticide formulation for long-lasting treatment of mosqutio nets. Malar J 2005, 4:52.

41. World Health Organization: Report of the eleventh WHOPES working group meeting. WHO/HTM/NTD/WHOPES/2008.1. Geneva: World Health Organizania Pesticide Evaluation Scheme; 2008.

42. Lines JD, Curtis CF, Wilkes TJ, Njunwa KJ: Monitoring human-biting mosquitoes (Diptera: Culicidae) in Tanzania with light-traps hung beside mosquito nets. Bull Entomol Res 1991, 81:77-84

43. Magbity EB, Lines JD, Marbiah MT, David K, Peterson E: How reliable are light traps in estimating biting rates of adult Anopheles gambiae s.l. (Diptera: Culicidae) in the presence of treated bed nets? Bull Entomol Res 2002, 92:71-76.

44. Gillies MT, De Meillon B: The Anophelinae of Africa south of the Sahara (Ethiopian Zoogeographical Region). Johannesburg: South African Institute for Medical Research; 1968. 
45. Gillies MT: A modified technique for the age-grading of populations of Anopheles gambiae. Ann Trop Med Parasitol 1958, 52:261-273.

46. Burkot TR, Williams JL, Schneider I: Identification of Plasmodium falciparum infected mosquitoes by a double antibody enzyme-linked immunosorbent assay. Am J Trop Dis Prevent Med 1984, 33(5):783-788.

47. Scott JA, Brogdon WG, Collins FH: Identification of single specimens of the Anopheles gambiae complex by the polymerase chain reaction. Am J Trop Med Hyg 1993, 49(4):520-529.

48. Smith T: Proportionality between light trap catches and biting densities of malaria vectors. J Am Mosq Control Assoc 1995, 11(3):377-378.

49. Davis JR, Hall T, Chee EM, Majala AR, Minjas J, Shiff CJ: Comparison of sampling anopheline mosquitoes by light-trap and human-bait collections indoors at Bagamoyo, Tanzania. Med Vet Entomol 1995, 9:249-255.

50. Woolhouse MEJ, Dye C, Etard JF, Smith T, Charlwood JD, Garnett GP, Hagan P, Hii JLK, Ndhlovu PD, Quinnell RJ: Heterogeneities in the transmission of infectious agents: Implications for the design of control programs. Proc Natl Acad Sci USA 1997, 94(1):338-342.

51. Smith T, Maire N, Dietz K, Killeen GF, Vounatsou P, Molineaux L, Tanner M: Relationship between the entomologic inoculation rate and the force of infection for Plasmodium falciparum malaria. Am J Trop Med Hyg 2006, 75(2_suppl):11-18.

52. Charlwood JD, Smith T, Kihonda J, Heiz B, Billingsley PF, Takken W: Density independent feeding success of malaria vectors (Diptera: Culicidae) in Tanzania. Bull Entomol Res 1995, 85:29-35.

53. Magbity EB, Lines JD: Spatial and temporal distribution of Anopheles gambiae s.l. (Diptera: Culicidae) in two Tanzanian villages: implications for designing mosquito sampling routines. Bull Entomol Res 2002, 92:483-488

54. Lindsay SW, Snow RW: The trouble with eaves; house entry by vectors of malaria. Trans R Soc Trop Med Hyg 1988, 82(4):645-646.

55. Kirby MJ, Green C, Milligan PM, Sismanidis C, Jasseh M, Conway D Lindsay SW: Risk factors for house-entry by malaria vectors in a rural town and satellite villages in The Gambia. Malar J 2008, 7:2.

56. Zuur AF, leno EN, Walker NJ, Saveliev AA, Smith GM: Mixed effects models and extensions in ecology with R. New York: Springer; 2009.

57. Killeen GF, Kihonda J, Lyimo E, Oketch FR, Kotas ME, Mathenge E, Schellenberg JA, Lengeler C, Smith TA, Drakeley CJ: Quantifying behavioural interactions between humans and mosquitoes: evaluating the protective efficacy of insecticidal nets against malaria transmission in rural Tanzania. BMC Infect Dis 2006, 6:161.

58. Lyimo IN, Ferguson HM: Ecological and evolutionary determinants of host species choice in mosquito vectors. Trends Parasitol 2009, 25(4):189-196.

59. Smith D, McKenzie FE: Statics and dynamics of malaria infection in Anopheles mosquitoes. Malar J 2004, 3(1):13.

60. Killeen GF, McKenzie FE, Foy BD, Schieffelin C, Billingsley PF, Beier JC: A simplified model for predicting malaria entomologic inoculation rates based on entomologic and parasitologic parameters relevant to control. Am J Trop Med Hyg 2000, 62(5):535-544.

61. Ijumba JN, Mosha FW, Lindsay SW: Malaria transmission risk variations derived from different agricultural practices in an irrigated area of northern Tanzania. Med Vet Entomol 2002, 16(1):28-38.

62. Zhou G, Munga S, Minakawa N, Githeko AK, Yan G: Spatial relationship between adult malaria vector abundance and environmental factors in western Kenya highlands. Am J Trop Med Hyg 2007, 77(1):29-35.

63. Diuk-Wasser M, Touré MB, Dolo G, Bagayoko M, Sogoba N, Sissoko I, Traoré SF, Taylor CE: Effect of rice cultivation patterns on malaria vector abundance in rice-growing villages in Mali. Am J Trop Med Hyg 2007 76(5):869-874

64. Le Menach A, Takala S, McKenzie FE, Perisse A, Harris A, Flahault A, Smith $D$ : An elaborated feeding cycle model for reductions in vectorial capacity of night-biting mosquitoes by insecticide-treated nets. Malar J 2007, 6(1):10.

65. Killeen GF, McKenzie FE, Foy BD, Schieffelin C, Billingsley PF, Beier JC: The potential impact of integrated malaria transmission control on entomologic inoculation rate in highly endemic areas. Am J Trop Med Hyg 2000, 62(5):545-551.

66. Marchant T, Bruce J, Nathan R, Mponda H, Sedekia Y, Hanson K: Monitoring and evaluation of the Tanzanian national net strategy: Report on 2008 NATNETS household, facility services and facility users surveys. Dar es Salaam: Ifakara Health Institute and London School of Tropical Medicine; 2009

67. Magesa SM, Wilkes TJ, Mnzava AE, Njunwa KJ, Myamba J, Kivuyo MD, Hill $\mathrm{N}$, Lines JD, Curtis CF: Trial of pyrethroid impregnated bednets in an area of Tanzania holoendemic for malaria. Part 2. Effects on the malaria vector population. Acta Trop 1991, 49(2):97-108.

68. Robert V, Carnevale P: Influence of deltamethrin treatment of bed nets on malaria transmission in the Kou valley, Burkina Faso. Bull World Health Organ 1991, 69(6):735-740.

69. Mosha FW, Lyimo IN, Oxborough RM, Matowo J, Malima R, Feston E, Mndeme R, Tenu F, Kulkarni M, Maxwell CA, et al.: Comparative efficacies of permethrin-, deltamethrin- and -cypermethrin-treated nets, against Anopheles arabiensis and Culex quinquefasciatus in northern Tanzania. Ann Trop Med Parasitol 2008, 102:367-376.

70. Saul A: Zooprophylaxis or zoopotentiation: the outcome of introducing animals on vector transmission is highly dependent on the mosquito mortality while searching. Malar J 2003, 2(1):32.

71. Burkot TR, Garner P, Paru R, Dagoro H, Barnes H, Barnes A, McDougall S, Wirtz RA, Campbell G, Spark R: Effects of untreated bed nets on the transmission of Plasmodium falciparum, P. vivax and Wuchereria bancrofti in Papua New Guinea. Trans R Soc Trop Med Hyg 1990, 84:773-779.

72. Bøgh C, Pedersen EM, Mukoko DA, Ouma JH: Permethrin-impregnated bednet effects on resting and feeding behaviour of lymphatic filariasis vector mosquitoes in Kenya. Med Vet Entomol 1998, 12:52-59.

73. Charlwood JD, Qassim M, Elnsur El, Donnelly M, Petrarca V, Billingsley PF, Pinto J, Smith T: The impact of indoor residual spraying with malathion on malaria in refugee camps in eastern Sudan. Acta Trop 2001, 80:1-8.

74. Hurd H: Manipulation of medically important insect vectors by their parasites. Annu Rev Entomol 2003, 48(1):141-161.

75. Habicht JP, Victora CG, Vaughan JP: Evaluation designs for adequacy, plausibility and probability of public health programme performance and impact. International Journal of Epidemiology 1999, 28:10-18.

76. Baragatti M, Fournet F, Henry MC, Assi S, Ouedraogo H, Rogier C, Salem G: Social and environmental malaria risk factors in urban areas of Ouagadougou, Burkina Faso. Malar J 2009, 8(1):13.

77. Graves PM, Richards FO, Ngondi J, Emerson PM, Shargie EB, Endeshaw T, Ceccato P, Ejigsemahu Y, Mosher AW, Hailemariam A, et al:: Individual, household and environmental risk factors for malaria infection in Amhara, Oromia and SNNP regions of Ethiopia. Trans R Soc Trop Med Hyg 2009 in press. Corrected Proof

78. Worrall E, Basu S, Hanson K: Is malaria a disease of poverty? A review of the literature. Trop Med Int Health 2005, 10(10):1047-1059.

79. Chuma J, Molyneux C: Estimating inequalities in ownership of insecticide treated nets: does the choice of socio-economic status measure matter? Health Policy Plan 2009, 24(2):83-93.

80. Lounibos LP: Competitive displacement and reduction. Bull AMCA 2007, 23:276-282.

81. Muriu SM, Muturi EJ, Shililu JI, Mbogo CM, Mwangangi JM, Jacob BG, Irungu LW, Mukabana RW, Githure JI, Novak RJ: Host choice and multiple blood feeding behaviour of malaria vectors and other anophelines in Mwea rice scheme, Kenya. Malar J 2008, 7:43.

82. Tirados I, Costantini C, Gibson G, Torr SJ: Blood-feeding behaviour of the malarial mosquito Anopheles arabiensis: implications for vector control. Med Vet Entomol 2006, 20:425-437.

83. Sharp BL, Le Sueur D: Behavioural variation of Anopheles arabiensis (Diptera: Culicidae) populations in Natal, South Africa. Bull Entomol Res 1991, 81:107-110.

84. Charlwood JD, Graves PM: The effect of permethrin-impregnated bednets on a population of Anopheles farauti in coastal Papua New Guinea. Med Vet Entomol 1987, 1:319-327.

85. Geissbühler Y, Chaki P, Emidi B, Govella NJ, Shirima R, Mayagaya V, Mtasiwa D, Mshinda H, Fillinger U, Lindsay SW, et al:. Interdependence of domestic malaria prevention measures and mosquito-human interactions in urban Dar es Salaam, Tanzania. Malar J 2007, 6:126.

86. Lindblade KA, Gimnig JE, Kamau L, Hawley WA, Odhiambo F, Olang G, Ter Kuile FO, Vulule JM, Slutsker L: Impact of sustained use of insecticidetreated bednets on malaria vector species distribution and culicine mosquitoes. J Med Entomol 2006, 43:428-432.

87. Bayoh MN, Mathias D, Odiere M, Mutuku F, Kamau L, Gimnig J, Vulule J, Hawley W, Hamel M, Walker E: Anopheles gambiae: historical population decline associated with regional distribution of insecticide- 
treated bed nets in western Nyanza Province, Kenya. Malar J 2010, $9(1): 62$

88. Gillies MT, Smith A: Effect of a residual house-spraying campagn on species balance in the Anopheles funestus group: The replacement of Anopheles gambiae Giles with Anopheles rivulorum Leeson. Bull Entomol Res 1960, 51:248-252.

89. Gillies MT, Furlong M: An investigation into the behaviour of Anopheles parensis Gillies at Malindi on the Kenya coast. Bull Entomol Res 1964, 55:1-16.

90. Rowland M, Durrani N, Kenward M, Mohammed N, Urahman H, Hewitt S: Control of malaria in Pakistan by applying deltamethrin insecticide to cattle: a community-randomised trial. Lancet 2001, 357(9271):1837-1841

91. Farenhorst M, Farina D, Scholte EJ, Takken W, Hunt RH, Coetzee M, Knols BGJ: African water storage pots for the delivery of the entomopathogenic fungus Metarhizium anisopliae to the malaria vectors Anopheles gambiae s.s. and Anopheles funestus. Am J Trop Med Hyg 2008, 78(6):910-916.

92. Cook SM, Khan ZR, Pickett JA: The use of push-pull strategies in integrated pest management. Annu Rev Entomol 2007, 52:375-400.

doi: $10.1186 / 1475-2875-9-187$

Cite this article as: Russell et al., Impact of promoting longer-lasting insecticide treatment of bed nets upon malaria transmission in a rural Tanzanian setting with pre-existing high coverage of untreated nets Malaria Journal 2010, 9:187

Submit your next manuscript to BioMed Central and take full advantage of:

- Convenient online submission

- Thorough peer review

- No space constraints or color figure charges

- Immediate publication on acceptance

- Inclusion in PubMed, CAS, Scopus and Google Scholar

- Research which is freely available for redistribution

Submit your manuscript at www.biomedcentral.com/submit
C) Biomed Central 